\title{
Enhancing metacognitive skillfulness of adolescents
}

\author{
Parul Kalia and Sarita Saini
}

Received: 24.01.2020; Revised: 08.03.2020; Accepted: 22.04.2020

See end of the paper for authors' affiliations

\section{Parul Kalia}

Department of Human

Development and Family

Studies, College of Community

Science, Punjab Agricultural

University, Ludhiana (Punjab)

India

Email : kalia.parulkalia.paru19@

gmail.com
ABSTRACT : Metacognition refers to one's "thinking about thinking" and is often defined by its accompanying skills such as monitoring and evaluation. Often researchers use metacognition as an overarching umbrella term but cognitive and educational theorists argue as to whether metacognition is a single construct or made up of distinct, differentiable factors. Metacognition has also been acknowledged as an abstract thinking ability known to enhance learning outcomes. The present research has made an attempt to assess the metacognitive skills among the students of the constituent colleges of PAU Ludhiana. The sample included 200 college students, in age range of 17-18 years. Metacognitive Awareness Inventory developed by Schraw and Dennison (1994) was used to measure the metacognitive skillfulness of the selected subjects and subsequently an attempt was made to prepare guidelines for parents and teachers to create a metacognitive environment since early years through daily interventions to strengthen their learning outcomes.

KEY WORDS: Metacognition, Planning, Evaluation, Debugging

- HOW TO CITE THIS PAPER : Kalia, Parul and Saini, Sarita (2020). Enhancing metacognitive skillfulness of adolescents. Asian J. Home Sci., 15 (1) : 38-43, DOI: 10.15740/HAS/AJHS/15.1/38-43. Copyright@ 2020: Hind Agri-Horticultural Society. 